\title{
NATURAL ATTENUATION FOR ECOSYSTEM RESTORATION IN NY/NJ HARBOR
}

\author{
D. van der Lelie and K. W. Jones \\ Brookhaven National Laboratory \\ Upton, New York 11973-5000 \\ J. D. Reid-Green \\ BASF Corporation \\ Mount Olive, New Jersey 07828-1234 \\ E. A. Stern \\ US Environmental Protection. Agency Region 2 \\ New York, New York 10007-1866
}

\begin{abstract}
Presented at
2nd International Conference on Remediation of Contaminated Sediments

Venice, Italy
\end{abstract}

30 September - 3 October 2003

By acceptance of this article, the publisher and/or recipient acknowledges the US government's right to retain a nonexclusive, royaltyfree license in and to any copyright covering this paper. 


\title{
NATURAL ATTENUATION FOR ECOSYSTEM RESTORATION IN THE NY/NJ HARBOR
}

\author{
D.van der Lelie (vdlelied@brnl.gov) and K. W. Jones \\ (Brookhaven National Laboratory, Upton, New York) \\ J. D. Reid-Green (BASF Corporation, Mount Olive, New Jersey) \\ E. A. Stern (U.S. EPA Region 2, New York, New York)
}

\begin{abstract}
We have investigated the feasibility of using natural attenuation methods for ecosystem restoration in New York/New Jersey Harbor. Measurements were made of the most probable number of sulfate-reducing bacteria (SRB) in native sediments and in samples, which had been supplemented with an appropriate electron donor and electron acceptor. The results showed that the activity of the endogenous microbial population in the native sediment was high enough to make possible adequate chemical transformation rates. The bioavailability of the zinc in the sediments was measured using the BIOMET biosensor technique. The bioavailability of the zinc was effectively eliminated following the microbial activities. We concluded that natural attenuation could be used effectively in treating sediments from Newark Bay and surrounding waters and that the resultant materials could likely be used in environmental restoration projects of the type proposed for construction in South Kearny, NJ.
\end{abstract}

\section{INTRODUCTION}

Industrial activities that support a large human population have also contaminated large volumes of sediments in the NY/NJ Harbor and have thereby caused serious deterioration in its ecosystem. Thus, there is great interest in producing a "green" Harbor that provides for the coexistence of the human activities with an improved state for the natural ecosystems. This is evidenced by the ongoing work of the NY/NJ Harbor Estuary Program on developing sediment management polices, reduction of point source discharges, remediation of contaminated regions in the aquatic environment, and restoration of brownfields. Examples of particular work sites relevant to ecosystem restoration are the Passaic and Hackensack Rivers and Newark Bay in New Jersey and Gowanus Canal and Newtown Creek in New York.

We focus here on a site at the tip of the peninsula (Kearny Point) formed by the confluence of the Passaic and Hackensack Rivers as they flow into the north end of Newark Bay. The BASF Corporation has proposed an ecosystem restoration in this confluence area that contains contaminated sediments from these two rivers. Using clean dredged material to cap and limit the bioavailability of the sediments, approximately 26 hectares (ha) of estuarine marsh and 16 ha of shallow subaqueous environment will be constructed in Newark Bay. The effectiveness of the cap is dependent on the natural populations of SRB in the sediments that can bring about a reduction in organic compounds and a change in the chemical state of the metals. We report the results of an investigation that shows that due to the activity of endogenous populations of sulfatereducing bacteria, the metals are found in the form of metal sulfite complexes that have very low dissociation constants under anaerobic conditions. Thus, they will only become 
soluble or bioavailable when the sediments change to an aerobic state. Therefore it is necessary to seal the sediments with a vegetation cap to prevent disturbance of the anaerobic state. Our measurements include use of BIOMET (Corbisier et al., 1999) sensors to obtain a clear picture of heavy metal bioavailability for $\mathrm{Zn}$, which also serves as a surrogate for other metals such as $\mathrm{Cd}, \mathrm{Cu}, \mathrm{Ni}$ and $\mathrm{Pb}$, and sediment toxicity. We are also using several techniques, including most probable number estimations on specific growth media (e.g., for consortia of sulfate-reducing bacteria) and molecular ecological techniques to examine community composition and functioning to measure the activity of the microbial populations. Using batch experiments, we found that a consortium of Desulfovibrio sp. (D. burkinabensis) and Clostridium sp. (C. glycolicum) is the primary engine to obtain the appropriate sulfate-reducing and metal-immobilizing conditions. The results of the experiments show that the Newark Bay sediments contain sufficient sulfate-reducing bacteria to minimize bioavailability and solubility of $\mathrm{Zn}$ and, by inference, other metals.

Application of Natural Attenuation to Dredged Material Management for the Port of NY/NJ. We envision a possible role for natural attenuation in plans for dredged material management in the Port of NY/NJ as well as for the type of environmental restoration discussed here. Dredging operations in the Port are restricted to a period of about six months so that there is no interference with spawning of fish. Much of the dredged material must be disposed of on land because of its possible harm to the marine environment if disposed of in the ocean. Further, dredging operations generate large amounts of material in very short time spans. Therefore, there is a need for temporary storage facilities, that is, a renewable confined disposal facility (RCDF), that serve as a buffer between the high-rate dredging operations and the processing required to modify the properties of the sediments to produce materials which can be utilized. Residence time for the sediment in the RCDF can be of the order of months thus introducing the possibility of treating them as a bioreactor where conditions are optimized for use of bacteria to reduce organic contaminants and to change the oxidation state of metals to render them less mobile. The treated sediments can then be used for possible environmental restoration projects such as the one described here.

Site Description. The restoration project being designed will be located in South Kearny, NJ at the northern end of Newark Bay. It was formerly used for chemical manufacturing facilities of the BASF Corporation. The land was created in past years with fill from various sources. Chemical contaminants are now being removed using a sediment/soil-washing process developed by BioGenesis Enterprises (Jones et al., 2001; Wenning et al., 2001). A sediment decontamination facility using the BioGenesis technology is being implemented on the site. It will have a storage facility that is potentially available for testing microbial attenuation as part of the treatment stream. The close proximity of the restoration area could provide a disposal area for several million $\mathrm{m}^{3}$ of sediment. A site diagram is shown in Figure 1. An aerial photograph of the site is shown in Figure 2. Actual restoration of the site depends on many factors such as funding, comprehensive evaluation of the environmental impact, granting of permits, etc. 


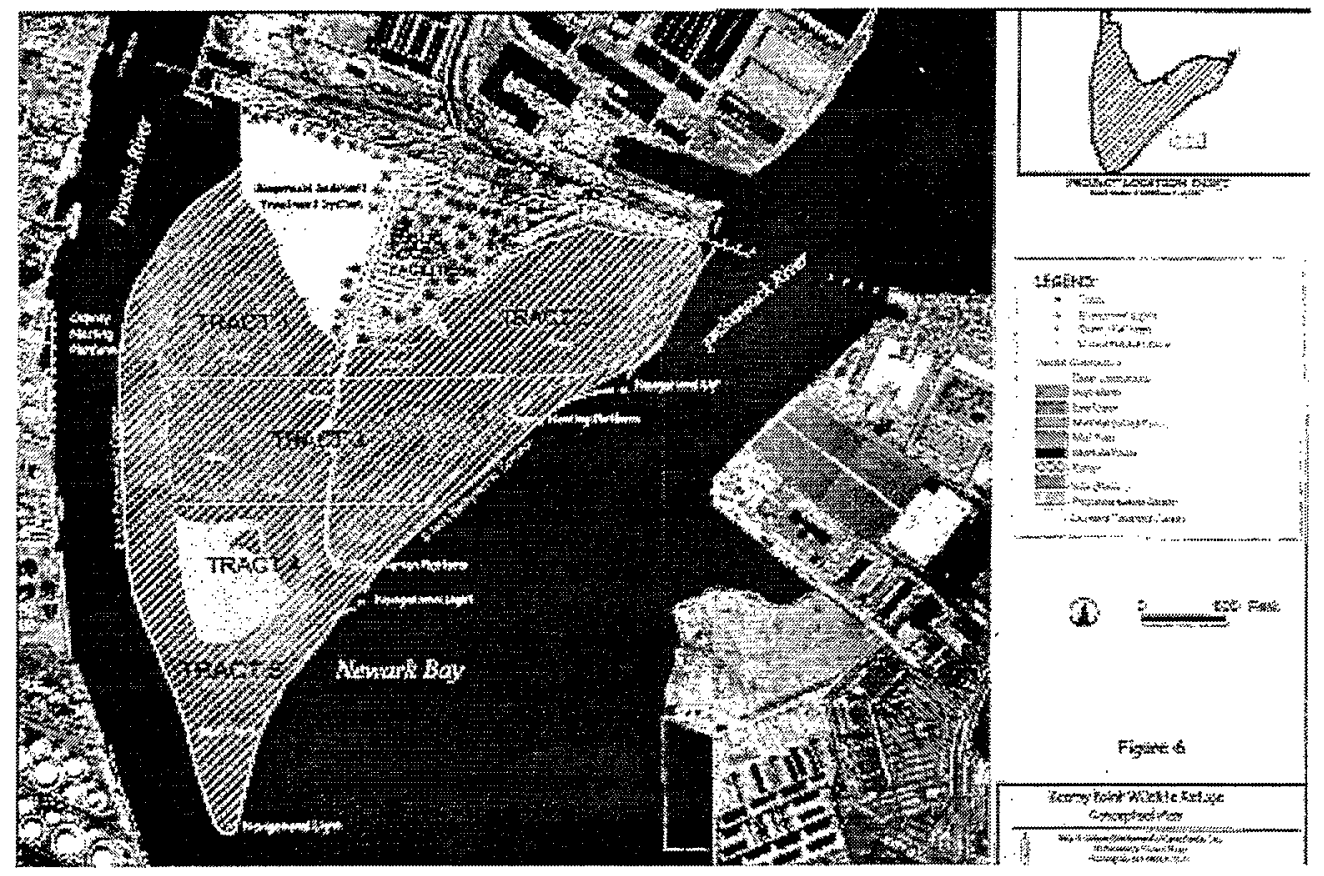

FIGURE 1. Map of proposed site for the ecosystem restoration project at South Kearny, New Jersey. The map shows the outline of the existing land and the extension to be created using dredged material. A portion of the existing area will be devoted to a dredged material processing facility using the BioGenesis sediment washing technology.

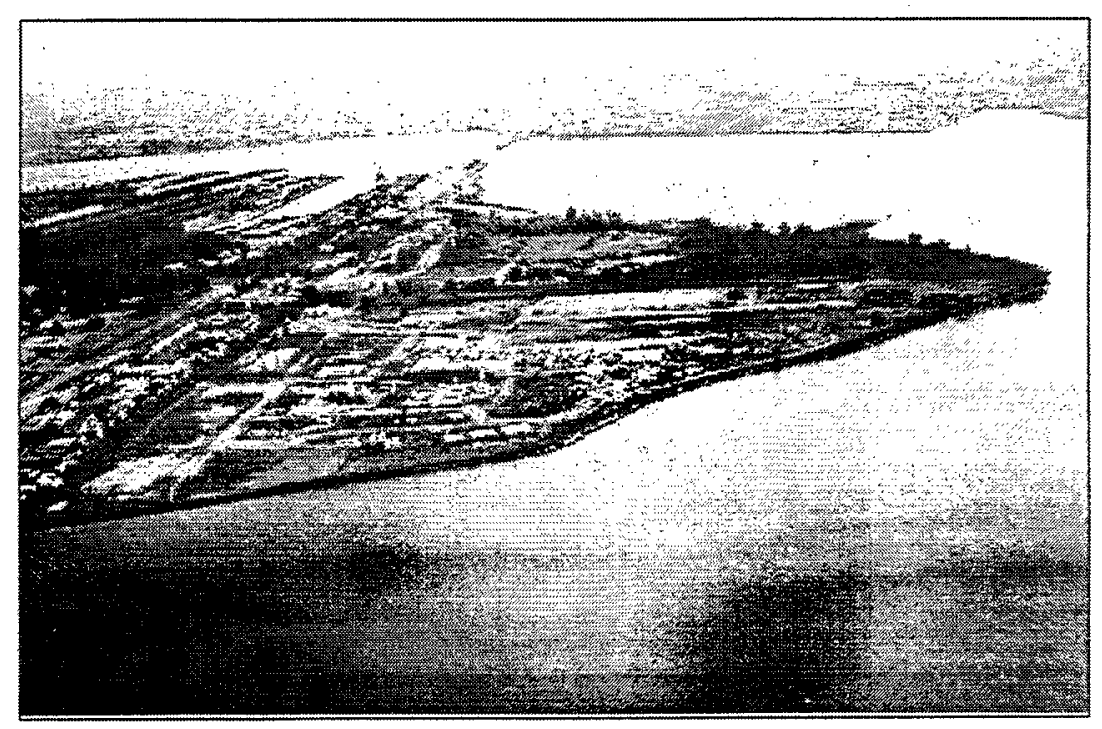

FIGURE 2. Aerial photograph of the proposed site viewed to the east. The towers of Manhattan can be seen in the far distance. The site is bounded on the east by the Hackensack River, on the west by the Passaic River, and on the south by Newark Bay. 


\section{MATERIALS AND METHODS}

Sample Site. The sample for this experiment was obtained just off the tip of Kearny Point at the junction of the Hackensack and Passaic Rivers. The sediment is from a mud flat that is exposed at low tide.

Sample Preparation. In order to stimulate the activity of the endogenous population of SRB present in NY/NJ harbor sediment, lactate $(2 \mathrm{~g} / \mathrm{l})$ and magnesium sulfate $(3.5 \mathrm{~g} / \mathrm{l})$ were used as electron donor and electron acceptor, respectively. The following batch treatments were prepared: Sediment plus lactate as electron donor and carbon source, sediment with sulfate as electron acceptor, sediment to which both acetate and lactate were added, and control sediment with no additions. The sediment was manipulated in an anaerobic chamber. Before being added, lactate and sulfate solutions were purged with nitrogen. All batches were incubated in the dark under anaerobic conditions. After two months, the batches were analyzed for the presence of SRB and for the bioavailability of the contaminating heavy metals, especially zinc which was the predominant heavy metal present.

Production of a beneficial use product from the cleaned sediment is highly desirable since it creates a revenue stream and reduces problems of the end disposal of the material. BASF has proposed the creation of a building product by mixing sediment particles with a polymer binder. Some of the test material was included in this experiment since it is important to know the bioavailability of the metals, such as $\mathrm{Zn}$, that are part of the product.

Analysis of Samples Using MPN Approach. The distribution and the effects of the addition of an electron donor or acceptor on the population of endogenous SRB present in NY/NJ harbor sediment was analyzed using most probable number (MPN) dilution. Postgate's B medium was prepared as described by Postgate (1984), and was used as an indicator for the presence of SRB. Serial dilutions of the sediment samples were made in triplicate. The cultures were incubated at room temperature, and the presence of SRB activity was determined after 2 weeks.

Analysis of Samples with the BIOMET Technique. The heavy metal specific BIOMET biosensors are based on the heavy metal resistant strain Ralstonia metallidurans $\mathrm{CH} 34$, which was isolated from a heavily contaminated decantation tank of a non-ferrous company. For this work we concentrated on the bioavailability of zinc, which was the predominant contaminant present in the NY/NJ sediment samples. The $\mathrm{Zn}$ resistance operon is located on plasmid pMOL30, one of the two endogenous megaplasmids (pMOL28 and pMOL30) of strain $\mathrm{CH} 34$ (for recent review, see Taghavi et al., 1997). The $P c z c \mathrm{~A}$ and $P c z c \mathrm{D}$ promoters, from which the structural zinc resistance proteins are transcribed, are induced when internal $\mathrm{Zn}$ concentrations exceed a certain threshold. Both RNA transcription studies and expression studies using reporter gene fusions showed a linear relation between the transcription levels of the structural resistance genes of the $c z c$ operon and the internal $\mathrm{Zn}$ concentration. The combined cadmium, zinc and cobalt resistance is based on efflux of the toxic metal, combined with post-efflux sequestration at the cell surface (probably due to complex formation with 
carbonates, bicarbonates and hydroxides) which prevents reentry into the cell (for a review of this process, see van der Lelie and Tibazarwa, 2001). In the BIOMET Znbiosensor, the bioluminescent luciferase operon (luxCDABE operon) of Vibrio fischeri is fused with the $c z c \mathrm{D}-c z c \mathrm{~S}$ region of the $c z c$ operon. As a result, the expression of the $l u x$ operon and thus the level of light production becomes zinc inducible, and will be in function of the bioavailable concentration of lead as determined by the cells. The advantage of the BIOMET biosensor is that it is currently one of the few available techniques that can give information on the actual bioavailable fraction of a metal species in a particular sample. In addition to the metal specific biosensor strain, we also use a constitutive strain. A decrease in light production for this strain indicates general toxicity.

Luminometry assay was carried out using an Luminescan luminometer (Labsystems OY, Helsinki, Finland) at $23^{\circ} \mathrm{C}$, as previously described (Corbisier et al., 1999). For metal standards, duplicate samples $(20 \mu 1)$ were set up per microtitre assay. As negative controls, eight reaction samples containing redistilled water were included in the test. Soils suspensions were made by adding $5 \mathrm{~g}$ soil to $35 \mathrm{ml} \mathrm{RM}$ medium, and $20 \mu \mathrm{l}$ of undiluted, 2 and 4 times diluted soil suspensions were added into wells of a 96-well microtitre plate. Subsequently, $180 \mu \mathrm{l}$ of the diluted $\mathrm{Zn}$ biosensor culture or the constitutative light-producing strain (final OD660 of 0.1 in RM medium) was added to each well. The bioluminescence emitted (ALU) and the optical density $\left(\mathrm{OD}_{620} \mathrm{~nm}\right)$ of the culture was measured over $16 \mathrm{~h}$ at $30 \mathrm{~min}$ intervals, and processed using the Excel software, as previously described (Corbisier et al., 1999). The induction of bioluminescence (presented as the signal to noise ( $\mathrm{S} / \mathrm{N}$ ) ratio) is calculated as the light production value (S) found for the soils tested, divided by the light production value found for the uncontaminated control soil $(\mathrm{N})$. A S/N value below 0.8 indicates toxicity, while a value above 0.8 indicates the presence of bioavailable metals. An induction is considered as significant when a $\mathrm{S} / \mathrm{N}$ ratio of at least 2 is found. With a calibration curve set up for $\mathrm{Zn}$, these ratios allow to calculate the amount of bioavailable $\mathrm{Zn}$ (mg $\mathrm{Zn}$ eq. $\mathrm{kg}^{-1}$ soil). The light production data of the constitutive strain then allows the calculation of the EC20 and EC50 toxicity values.

\section{RESULTS AND DISCUSSION}

Presence of Sulfate Reducing Bacteria. Initial plating experiments of diluted sediment samples on Postgate B medium revealed the presence of sulfate reducing bacteria: these bacteria form black colonies on this indicator medium, this as a result of iron-sulfide formation. A photograph of a colony is shown in Figure 3. The results of the MPN countings performed on the different batches of treated sediment showed that a population of endogenous SRB is present in the NY/NJ harbor sediment, and that this population can be strongly increased when an appropriate electron donor and acceptor are added. In the case when both lactate and sulfate were added, the SRB population increased 100,000 fold over a two-month period. This is shown qualitatively in Figure 4. 


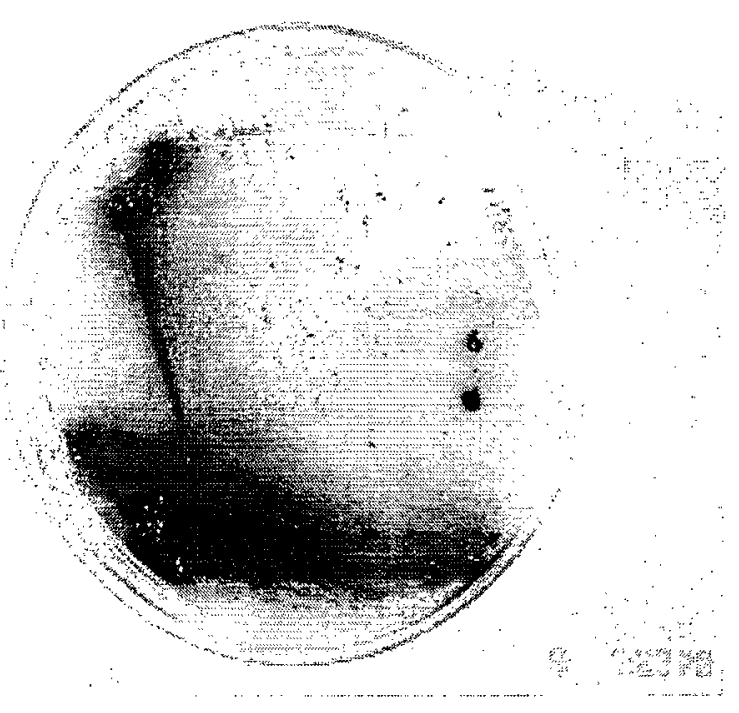

FIGURE 3. Growth of sulfate-reducing bacteria on Postgate B medium.

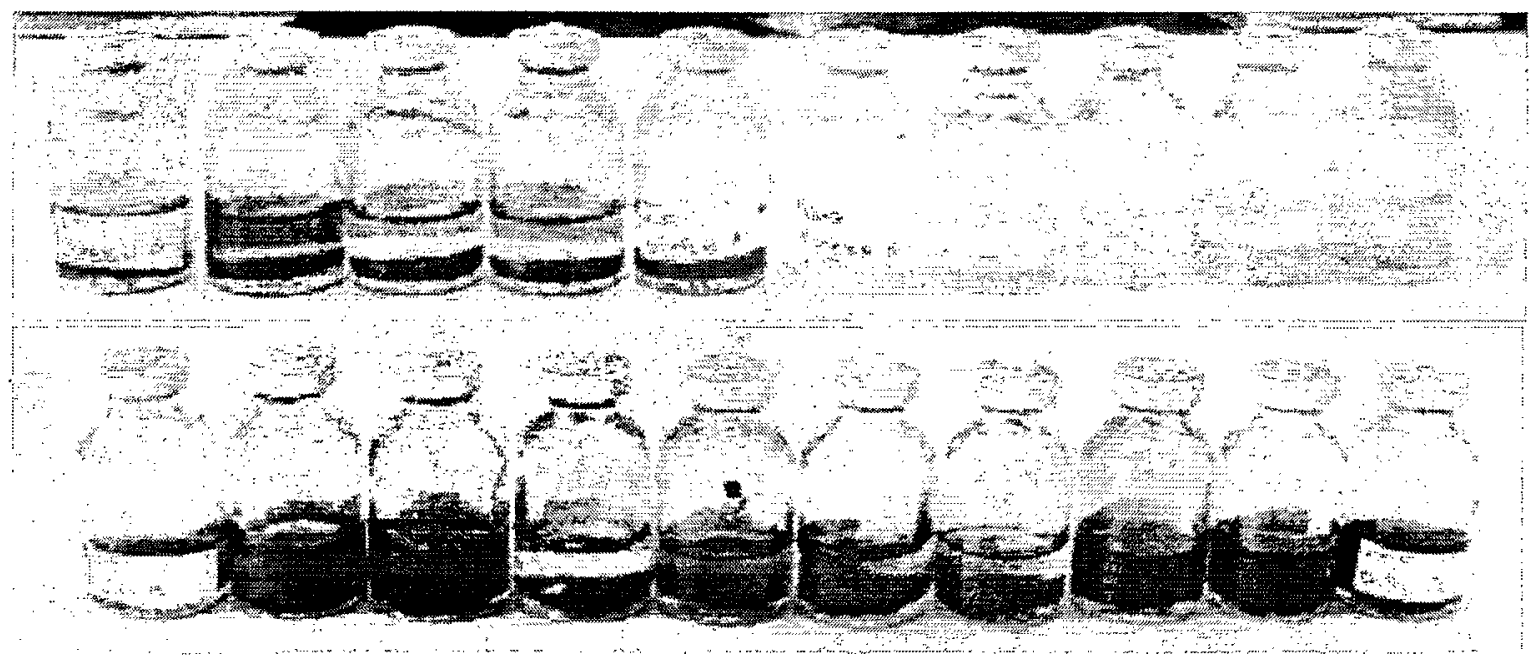

FIGURE 4. Evaluation of MPN for sulfate-reducing bacteria. The liquids in the bottles have been diluted by a factor of 10 between each bottle. The highest concentrations are at the left. The presence of sulfides is indicated by conversion of the sediment to a black color. The top photograph shows the effects of the bacterial action on a control sample of sediment. The bottom photograph shows the effect of adding acetate and sulfate to the sediment. The addition of the acetate and sulfate has clearly improved the effectiveness of the microbial action.

The microbial community present in the NYNJ harbor was examined using a combination of molecular techniques and strain cultivation. We found that a consortium of Desulfovibrio sp. (D. burkinabensis) and Clostridium sp. (C. glycolicum) is the 
primary engine to obtain the appropriate sulfate-reducing and metal-immobilizing conditions.

Have Soil Washing and Polymer Addition an Effect on Sediment Quality? The BIOMET test was used to examine the effects of soil washing and polymer addition on sediment quality. The results are presented in Table 1 . The BIOMET data showed that the untreated sediment was toxic, and that about $40 \%$ of the $\mathrm{Zn}$ was present in a bioavailable form. Soil washing resulted in a complete removal of the bioavailable zinc. However, the data of the constitutive biosensor strain showed that other pollutants that are responsible for the observed toxicity remained present after sediment washing (BioGenesis Enterprises, Oak Creek, WI 53154). On the other hand, the addition of the polymer resulted in a strong decrease of the sediment toxicity. However, the polymer addition had no effect on the $\mathrm{Zn}$ bioavailability. This indicates that toxicity is caused by large organic molecules, such as PAHs, that are efficiently trapped by the polymer, this in contrast to $\mathrm{Zn}$ and presumably other heavy metals, heavy metals whose bioavailability is not affected by the polymer addition.

TABLE 1. Results of BIOMET measurements of zinc toxicity in NY/NJ Harbor sediment.

\begin{tabular}{|lccc|}
\hline \multicolumn{1}{|c}{ Sample } & Total Zinc & Bioavailable Zinc & Toxicity Value \\
\hline Contaminated Harbor sediment & 485 & 175 & Toxic \\
Soil-washed Harbor sediment & 439 & $<10$ & Toxic \\
$\begin{array}{l}\text { Polymer-treated Harbor } \\
\text { sediment }\end{array}$ & 168 & 162 & Not toxic \\
\hline
\end{tabular}

Total zinc in ppm. Bioavailable zinc in ppm per kg dry weight sediment.

Does the Presence and Activity of SRB Effect the Bioavailability of Heavy Metals? It is expected that due to the activity of SRB the bioavailability of heavy metals in the sediment will be reduced. In the case of $\mathrm{Zn}$ it is expected that the metals will be precipitated in the form of $\mathrm{ZnS}$ which is insoluble under anaerobic conditions. The potential decrease in $\mathrm{Zn}$ bioavailability was tested using the zinc specific biosensor strain AE1433. The results are presented in Table 2 and show that even in the untreated sediment the bioavailability fraction of zinc was below $50 \mathrm{ppm}$, which is the detection limit of the test. When compared with earlier results in Table 1 this indicates that the incubation of the sediment under strict anaerobic conditions results in a strong decrease of $\mathrm{Zn}$ bioavailability. This shows that the presence of the natural population of SRB in the NY/NJ Harbor sediment is sufficient to strongly reduce the $\mathrm{Zn}$ bioavailability and thus its environmental impact, as long as the sediment is kept under the appropriate, anaerobic conditions. Similar results were obtained when an extra electron donor or acceptor were added to the sediment. 
TABLE 2. Measurement of natural attenuation of $\mathrm{Zn}$ bioavailability and redox potential over a 7-week period.

\begin{tabular}{|lcc|}
\hline \multicolumn{1}{|c}{ Sample } & T0 & T7 \\
\hline Control & 721 & $<50$ \\
+ Acetate & 721 & $<50$ \\
+ Sulfate & 721 & $<50$ \\
+ Acetate + Sulfate & 721 & $<50$ \\
NIST Standard Reference & 609 & $<50$ \\
Material 1944, NY/NJ & & \\
Waterway Sediments & & \\
\hline
\end{tabular}

$\mathrm{Zn}$ bioavailability is expressed in $\mathrm{mg} / \mathrm{kg}$ sediment dry weight. The minimum detection limit is $<50 \mathrm{mg} / \mathrm{kg}$ sediment dry weight.

\section{CONCLUSIONS}

This investigation showed that SRB are present in the Newark Bay sediment that was the subject of the experiment. The SRB existed in sufficient amounts to cause natural attenuation of biotoxicity for $\mathrm{Zn}$ and a reduction in redox potential. Addition of sulfate and acetate to the sediments increased the number of SRB and hence their effectiveness for natural attenuation. Testing of a polymer/sediment composite material proposed for construction purposes showed that the material was not toxic for the $\mathrm{Zn}$ Biomet test.

The results encourage the view that natural attenuation could be useful in treatment of stored sediments prior to application of sediment washing or other decontamination technologies or for disposal in ecosystem restoration or brownfield remediation projects under anaerobic conditions. Further, the use of sediments in a polymeric/sediment composite showed no adverse toxicity effects.

These initial results suggest that further investigations on the bench-, pilot-, and full scales are justified. The work needs to be extended to a consideration of the effects of organic compounds and of other metals in sediments more highly contaminated than the specimens used in this experiment. This would verify the effectiveness over a broader range of contaminants and also provide a more precise view of the decomposition products and the rates at which compounds are destroyed or modified. The results would then be the basis for field-deployment of natural attenuation as part of the plan for dredged material management and environmental restoration in the NY/NJ Harbor. 


\section{ACKNOWLEDGEMENTS}

Research supported in part by the U.S. Department of Energy under Contract No. DE-AC02-98CH10886 (DVDL and KWJ) and through Interagency Agreement DW89941761-01 between the U.S. Environmental Protection Agency and the U.S. Department of Energy (KWJ).

\section{REFERENCES}

Corbisier, P., D. van der Lelie, B. Borremans, A. Provoost, V. de Lorenzo, N. L. Brown, J. R. Lloyd, J. L. Hobman, E. Csöregi, G. Johansson, and B. Mattiasson, B. 1999. "Whole Cell- and Protein-Based Biosensors for the Detection of Bioavailable Heavy Metals in Environmental Samples." Anal. Chem. Acta 387: 235-244.

Jones, K. W., H. Feng, E. A. Stern, J. Lodge, N. L. Clesceri. Dredged material decontamination demonstration for the port of New York / New Jersey. Journal of Hazardous Materials 85 (2001) 127-143.

Postgate, J.R. 1984. The Sulphate Reducing Bacteria. Cambridge University Press, Cambridge, Great Britain.

Taghavi, S., M. Mergeay, D. Nies, and D. van der Lelie. 1997. "Alcaligenes eutrophus as a Model System for Bacterial Interactions with Heavy Metals in the Environment." Res. Microbiol. 148(6), 536-551.

van der Lelie, D., and C. Tibazarwa. 2001. "Bacteria." In A. Prasad (Ed.), Metals in the Environment: Analysis by Biodiversity, pp. 1-36. Marcel Dekker, New York, NY.

Wenning, Richard J., Eric A. Stern, Keith W. Jones, and W. Scott Douglas. 2001. "The WRDA Program and Emerging Decontamination Technologies for Contaminated Sediments. Contaminated Soil, Sediment and Water, December 2001, pp. 38-41. 